\title{
A customer portfolio management model that relates company's marketing to its long-term survival
}

\author{
Leigh McAlister ${ }^{1} \cdot$ Shameek Sinha $^{2}$ (D) \\ Received: 9 July 2019 / Accepted: 8 December 2020 / Published online: 28 January 2021 \\ (C) Academy of Marketing Science 2021
}

\begin{abstract}
A typical customer relationship management model is designed to increase the value of a company's existing customers in the next period. While useful in the short term, such a process, followed blindly period after period, would drive the company out of business when those existing customers all eventually died. In reality, no company would do this. Instead, these short-term models are nested within a long-term view of customer management, and it is long-term customer management that the proposed model addresses. The model assumes that a company has identified a set of customer types across which it needs balance in order to remain viable in the long-term (e.g., a company might wish to maintain a supply of "entry-level customers" in order to eventually replenish its collection of more profitable "loyal customers"). Though the model is applicable in any industry, we illustrate it for automobiles. Results reveal the strengths with which each marketing intervention causes General Motors to attract each of their desired customer types. The model is extended to also reveal differences in the ways that marketing interventions by Ford, Toyota, and Honda change the strengths with which those automakers attract customers.
\end{abstract}

Keywords Customer portfolio management $\cdot$ Customer mix $\cdot$ Long-term vs. short-term, attracting customers $\cdot$ Company survival

\section{Introduction}

The question of whether and how marketing influences company performance is central to marketing management. The macro-level stream of this research searches for a relationship between a company's marketing as a whole and the company's performance as a whole (e.g., Moorman and Day, 2016). The micro stream of this research searches for a relationship between a particular marketing intervention and a particular marketplace outcome (e.g., Guadagni and Little, 1983). All of these models, we will argue, are short term, because the marketplace outcomes on which they focus represent short-

Neil Morgan served as Area Editor for this article.

Shameek Sinha

shameek.sinha@devinci.fr

Leigh McAlister

leigh.mcalister@mccombs.utexas.edu

1 Department of Marketing, McCombs School of Business, University of Texas at Austin, Austin, TX 78730, USA

2 EMLV Business Group, Leonard de Vinci Pole Universitaire, Research Center, 92916 Paris, La Defense, France term performance and because these models consider only a company's current customers.

We propose a new model that complements these macro and micro models by assessing the relationship between marketing and a company's customer mix, where managing that customer mix is related to the company's problem of remaining viable in the long-term. Existing customer relationship management (CRM) models prescribe methods for calculating a customer's exact value in the short term, and it is easy to imagine that an entry-level customer will be less valuable than a loyal customer on those short-term measures. An approach designed to maximize short-term performance is therefore likely to prioritize loyal customers over entry-level customers. One need not calculate a customer's exact long-term value to see that a company's customer mix needs to include a balance of entry-level customers and loyal customers if the company is to remain viable in the long-term.

Customer portfolio management (CPM) differs from CRM by considering a small number of customer types of interest to the company rather that dealing with every customer individually. CPM de-emphasizes the estimation of customer value and, instead, assumes that customer types' values are known. When a set of customer types is defined so that each successive customer type is more valuable than the previous, 
customer types can be thought of as steps through which the company would like to take every customer; at each step, transforming the customer into the next, more valuable customer type. In this situation, CPM resembles CRM: The company seeks interventions that will influence customers of one type to become, next period, customers of a more valuable type. In this spirit, some CPM models can be thought of as a tool, like Venkatesan and Kumar's (2004) CRM tool, for increasing customers' values next period. For example, Homburg et al. (2009) identified customer types based on a customer's recent spending. They considered whether a company's next period payoff would be greater with an intervention that caused customers to become more valuable next period or with an intervention that prevented customers from becoming less valuable next period. Netzer et al. (2008) were concerned with switching an alumnus from being "dormant" (i.e., having only a $6 \%$ chance of giving) this period to being "occasional" (i.e., having a $46 \%$ chance of giving) next period or switching a this-period "occasional" to being next-period "active" (i.e., having a 100\% chance of giving).

It is important to note that all of the models discussed above calculate a customer's value from that customer's purchasing history (e.g., Holm et al., 2012). Though some models attempt to "look ahead" at expected purchases in the near future (e.g., Rust et al., 2011), it is beyond the scope of the customer transaction data bases on which these models are built to assess, with any accuracy, the value that a customer will provide to the company over the next 30-50 years. Partly because of this, we refer to these models as "short term."

We refer to the proposed model as "long term" because, without estimating a specific dollar value for a given customer type, the proposed model can help a company maintain the customer mix balance it needs to remain viable in the long term. For example, a company might wish to maintain a balance of loyal customers and entry-level customers because loyal customers provide more value in the short term, but entry-level customers (eventually developed into the loyal customers) will sustain the company's viability when its current loyal customers die off. By focusing on the company's ability to attract different customer types, the proposed model provides a tool which estimates the customer type-specific impact for each marketing intervention. Understanding the customer type-specific impact of different marketing interventions equips a company to develop a collection of marketing interventions that can be expected to maintain the company's desired customer mix.

Johnson and Selnes (2004) were the first to explicitly formulate a long-term model of customer portfolio management. They defined customer types by the stage of the company's relationship with the customer and called for balance across those customer types. They made the point that a company must replenish its supply of entry level customers or eventually fail. We note, though, that their model was completely conceptual.

The proposed CPM model can be thought of as operationalizing Johnson and Selnes' (2004) conceptual model. The proposed model begins by identifying a few customer types across which a company needs balance in order to maintain long-term viability. Based on data which includes changes, over time, in the percent of a company's customer mix that is made up of each of the customer types, estimated model parameters report the relationship between a company's marketing intervention and changes in that customer mix. That is, the proposed model is a measuring instrument. It measures the influence of a company's marketing on the strength with which that company attracts different customer types, i.e., it reports the influence of a company's marketing on it's customer mix. Though we leave to future research the problem of defining a company's optimal customer mix, we note that once that optimal mix has been determined, a company can use the proposed model's parameters to prescribe a set of marketing interventions that would be expected to yield that optimal customer mix.

Consider Christian Louboutin, whose customers can be thought of as "insiders" who have high fashion-domainspecific cultural capital and "outsiders" who do not. Louboutin could use the proposed model to help protect their ability to charge thousands of dollars for a pair of shoes. To protect that pricing power, Louboutin's marketing must restrict imitation by outsiders and make the insiders' taste hard to copy. That is, Louboutin's marketing should consist of subtle signals that are observable to insiders who have the necessary connoisseurship to decode their meaning but should not be observable by outsiders, thus providing value to insiders by classifying them as possessing fashion culture capital and by facilitating their communication with others "in the know" (Berger and Ward 2010). Louboutin needs marketing interventions that strengthen its ability to attract one customer type while having no impact on the strength with which it attracts another customer type. By giving Louboutin a mechanism for measuring the impact of a marketing intervention on the strength with which it attracts each customer type, the proposed model could provide Louboutin with the ability to identify marketing interventions that attract "insiders" while remaining invisible to "outsiders."

As another illustration, consider the usefulness of the proposed model for Seventh Generation dish soap. Assume that Seventh Generation has two types of customers ("high involved with sustainable consumption" and "low involved with sustainable consumption") and that Seventh Generation's brand equity rests on the fact that Seventh Generation is bought by customers that are "high involved with sustainable consumption." Edinger-Schons et al. (2018) tell us that both customer types increase purchase intention when exposed to an intrinsic motivation communication ("Do something good 
for the environment by buying Seventh Generation"), but that only "low involved with sustainable consumption" customer types increase purchase intention when exposed to an extrinsic motivation communication ("Show your friends and relatives how sustainable you are"). Because both intrinsic and extrinsic motivation communications are expected to increase next period's sales, short-term CRM and CPM models would support the use of both intrinsic and extrinsic motivation communications.

Unfortunately, Edinger-Schons et al. (2018) also tell us that exposure to the extrinsic motivation communication actually has the unintended consequence of reducing, for the "high involved with sustainable consumption" customer type, the belief that Seventh Generation acts out of genuine concern to be socially responsible. This reduction in esteem for Seventh Generation is expected to reduce the strength with which Seventh Generation attracts "high involved with sustainable consumption" customer types, and losing its ability to attract this customer type undermines Seventh Generation's brand equity. To uncover this problem, Seventh Generation needs a model that allows a marketing intervention to have a different impact on each customer type. By communicating an extrinsic message, Seventh Generation might increase the strength with which it attracts "low involved with sustainable consumption" customers but that communication also has the unintended consequence of alienating "high involved with sustainable consumption" customers. If Seventh Generation doesn't identify this sales-increasing, extrinsic communication as problematic, their use of that extrinsic communication could inadvertently drive away the very customers on which their brand's image is based. Once those "high involved with sustainable consumption" consumers have been driven away, Seventh Generation is also likely to lose its ability to attract "low involved with sustainable consumption" consumers because those consumers would no longer view Seventh Generation as emblematic of sustainable consumption. By giving Seventh Generation a tool that measures the impact of a marketing intervention on each customer type, the proposed model could alert Seventh Generation to the fact that the extrinsic communication reduces the strength with which Seventh Generation attracts "high involved with sustainable consumption consumers" even as that advertisement increases Seventh Generation's next period sales.

The problem of marketing interventions having opposite effects for different, valuable customer types afflicts many companies other than Seventh Generation. One particular pair of customer types likely to be valuable to product makers and for which such opposite effects can be anticipated is "younger" customers and "older" customers. iPhone and Facebook found that success in selling to older customers made it more difficult to sell to younger. Older voters support for Trump inclines younger voters to reject him. Motorcycles, boats, snowmobiles, and other recreational vehicles were once sold successfully to baby boomers, but those companies now find it difficult to attract younger customers (Tita 2020). With powerful brand loyalty, a product maker that can maintain a customer mix balanced across youth, adults, and seniors is poised to thrive. However, if those interventions that attract older customers who are more profitable in the short term tend to drive away the younger customers, who are less profitable in the short run but critical for survival, the company has a customer management problem. It will be critical for the company to understand which interventions act oppositely on younger versus older customers so that such interventions can be avoided. By giving these companies a mechanism for measuring the impact of a marketing intervention on each customer type, the proposed model can assist them with their long-term customer management problem.

Harley-Davidson ("Harley") is a company whose marketing may have opposite effects on the strengths with which it attracts "younger" and "older" customer types. Harley's customers' average age is over 50 and whose sales and its stock price fell steadily between 2015 and 2019 (Sozzi, 2019). Joe Altobello, an analyst at Raymond James, notes that "Harley is in a tough spot here, where their core constituency is getting older and they are having a tough time attracting... younger [riders]" (Ferris, 2019). In an attempt to attract younger riders, Harley spent hundreds of millions of dollars on R\&D to "freshen up" its product line with nearly silent, electric motorcycles (Sozzi, 2019). Harley sponsored the $\mathrm{X}$ Games in the hope of appearing "cool" to millennials. They are nurturing a new generation of U.S. riders with learn-to-ride programs (Tita, 2020).

Are their new electric motorcycles, sponsoring the $\mathrm{X}$ Games, and learn-to-ride programs the right marketing interventions? Do these interventions help Harley attract younger riders? What unintended consequences might these interventions have for Harley's older, core constituency - the HOGs (Harley Owners Group)? What happens to the strength with which Harley attracts HOGs when, as a part of this marketing, the CEO refers to HOGs as "old white guys" (Sozzi, 2019) and when blog posts by the young customers Harley courts deride HOGs as "a bunch of salty old bags dissatisfied with their lives" or "dust buckets complaining about being left behind"? These are questions that can be addressed with the proposed model.

In summary, it is not always sufficient to know the impact of a marketing intervention on next period's sales. In many cases, a company needs to know to whom those sales were 
made. Understanding the influence of a marketing intervention on different customer types, the company can construct a portfolio of marketing interventions that ensure the appropriate balance in the company's customer mix, and help ensure the company's long-term viability.

In the next section, we summarize customer portfolio management models by sorting them into a $2 \times 2$ table (short vs. long term, marketing drivers vs. not) and touch on three additional advantages for the proposed model. After positioning the proposed customer portfolio management model, we present the model's underlying logic and then illustrate the model by applying it to General Motors, a company that needs a balance of younger and older customers in order to thrive. We describe our automotive industry data and the proposed model before estimating the General Motors model and then extending the model to also consider Ford, Honda, and Toyota. We end with a discussion including implications for managers, the model's limitations, and directions for future research.

\section{Customer portfolio management models}

All customer portfolio management models begin by identifying customer types. ${ }^{1}$ The grouping of customers into customer types should be done in a way that is consistent with business practice (Rust et al., 2000) because it enhances the efficiency of marketing spending (Mulhern 1999; Zeithaml et al., 2001; Reinartz and Kumar 2003; Kumar et al., 2008; Fader 2012) and because it results in implications on which a manager can act. Parasuraman and Colby (2001) define customer types by level of technological readiness, and FedEx defines customer types as "the good," "the bad," and "the ugly" (Brooks 1999). More broadly, McKinsey (2017) advises that customer types be defined in the way managers find useful, whatever that might be. For our automotive industry example, we define customer types as Youth, Adults, and Seniors for the models.

Table 1 contrasts the proposed customer portfolio management model with brand choice (marketing mix) models, transaction-based CRM models, Johnson and Selnes' (2004) conceptual customer portfolio management model, and Netzer et al.'s (2008) and Homburg et al.'s (2009) empirical customer portfolio management models.

The first two columns of Table 1, representing models that are not concerned with managing customer portfolios, are

\footnotetext{
${ }^{1}$ Johnson and Selnes talk about "customer segments" rather than about "customer-types." However, Terho and Halinen (2007) point out that using the term "segment" in customer portfolio management may cause confusion. A segment is a distinct subset of the market as a whole, while customer portfolio management is concerned with distinct subsets of the company's current customers.
}

included as widely used models against which to contrast the portfolio models.

The fourth row of Table 1 illustrates the point made in the introduction that most of the surveyed models are short-term, designed to increase return next period. Only Johnson and Selnes' (2004) conceptual model and the proposed customer portfolio management model address the long-term problem of maintaining the customer mix a company needs for survival in the long-term. The sixth row shows that other CRM and CPM models do not incorporate marketing as a force that shapes marketplace outcomes. This happens because the vendor transaction databases on which these models are estimated do not carry much marketing information. Netzer et al. (2008) did incorporate forces that influenced customer mix, but those were not marketing forces. ${ }^{2}$

Table 2 can be thought of as summarizing Table 1 in a way that highlights the most important contributions of the proposed customer portfolio management model. This model is the first to both focus on the long-term balance in a company's customer mix and also consider the way in which marketing can be used to help maintain that balance.

The proposed model's other distinctions, visible in Table 1 (row 7), are that the proposed model, by estimating the impact of marketing on the strengths with which the company attracts each of its focal customer types, is the only model that can track potentially unintended consequences of marketing decisions. ${ }^{3}$ Because the proposed model is estimated with data from successive waves of a nationally projectable survey, the proposed model gets information on, and can thus incorporate competition (row 9). Because the proposed model is based on surveys rather than on a long history of purchases for individual customers, the proposed model can be estimated for long purchase cycle durable products ${ }^{4}$ (row 10).

\footnotetext{
${ }^{2}$ Netzer et al. (2008) identify three forces that influence whether a customer will change from one type to another in a particular year: whether the year in question is a reunion year for the alum, whether the alum has participated in a reunion since graduation, and whether the alum has volunteered for a university role after graduation. These customer mix changing forces are alum's actions. The university's marketing could have triggered these actions, but interactions with other alums (Zhang 2019) or some other, unidentified force could also have triggered these changes.

${ }^{3}$ Note that marketing mix models estimate the influence of a marketing intervention on overall sales. What they cannot do is report the kinds of customers to whom those sales were made. Consequently, marketing mix models cannot identify unintended consequences of a seemingly "successful" marketing intervention. For example, an extrinsic motivation communication might increase sales for Seventh Generation, but that sales increase would come with the unanticipated consequence of alienating "high involved with sustainable consumption" consumers, the group on which Seventh Generation's brand equity rests.

${ }^{4}$ Because a given customer purchases a durable only infrequently, durable companies cannot accumulate the many transactions per customer needed to estimate transaction-based customer relationship management models, Netzer et al. (2008) or Homburg et al. (2009). A durable company can, though, observe its marketing and its customer mix each period, and with a suitable number of such observations, estimate the parameters of the proposed customer portfolio management model.
} 


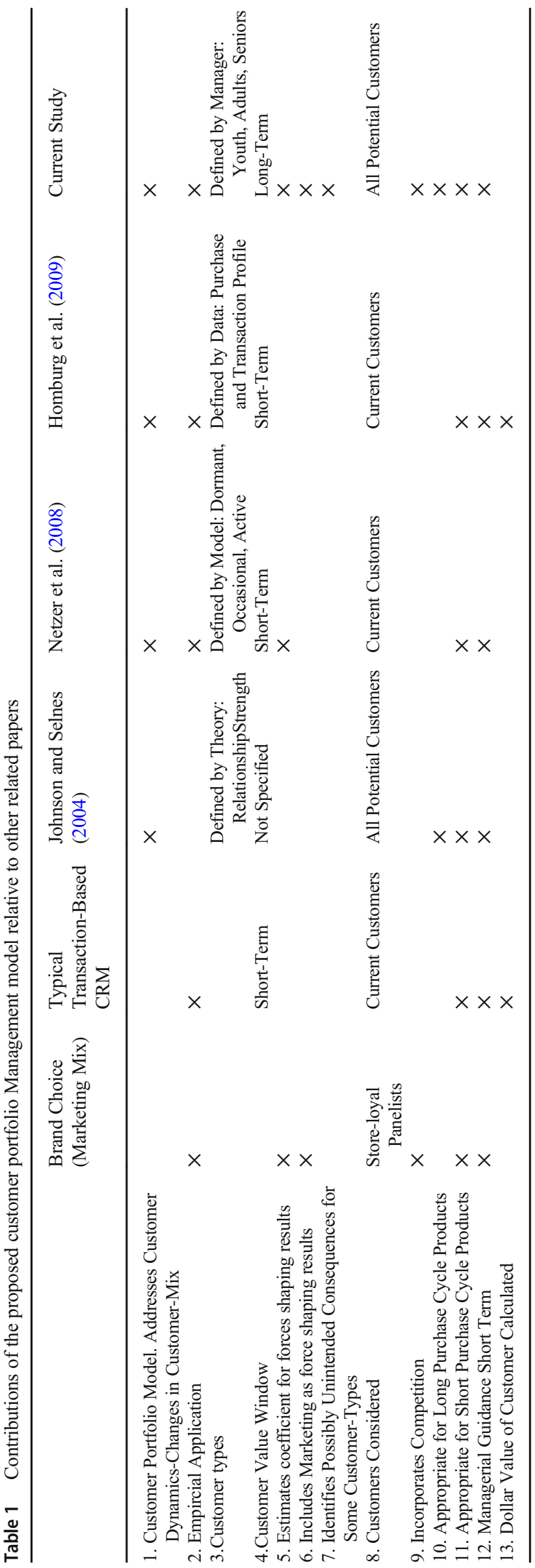

\section{Empirical example: General Motors and the auto industry}

We begin by noting that age cohort customer types (i.e., Youth, Adults, Seniors) make sense in the auto industry. We know that a customer's buying power is likely to increase as that customer gets older. In addition, automobile features sought by a new, 16-year-old driver are likely to be quite different from the features sought by a 35 -year-old adult with two children which are, in turn, likely to be quite different from the features sought by a 60 -year-old grandparent. Finally, we note that brand loyalty is high for automobiles (Welsh, 2013), suggesting that an automaker that captures a young autobuyer is more likely to be able to keep selling its vehicles to that autobuyer when she or he becomes an Adult, and later a Senior. All of this suggests that an automaker needs to maintain a balance of Youth, Adult, and Senior customers and to do that, the automaker needs to understand the vehicle features and other marketing interventions that attract each of these customer types.

We begin by building a customer portfolio management model for General Motors, a company that seems to be seeking balance in its customer mix. They responded to Buick's average buyer age of 57 by launching the 2013 Buick Encore, targeted to young buyers (Wayland 2013). They were unhappy when sales of much-heralded Volt, designed for Youth, began to sag (Taylor 2013). The 2015 Chevrolet Colorado and 2015 GMC Canyon were trucks designed for young buyers (McEachern 2014).

With customer types defined by age cohorts (i.e., Youth, Adults, Seniors), estimated parameters from the proposed model can provide General Motors with guidance for re-balancing its customer mix. For example, if General Motors wants to draw more Youth into their customer mix, they should invest more in the marketing elements that model parameters indicate contribute most to the strength with which General Motors attracts Youth. Further, by using the proposed model to understand how Ford, Toyota and Honda attract Youth, Adults, and Seniors, the proposed model provides General Motors with valuable competitive insight.

\section{Data}

Previous customer portfolio management models worked with the transaction database for a vendor's current customers, creating estimates of customer value based on those historical transactions. The proposed customer portfolio management model moves beyond transaction databases for several reasons. First the proposed model does not need historical transactions to infer a customer's long-term value. (Looking 
Short-Term Model

(Customer value based on historical purchases, doesn't address balance)

Typical transaction-based CRM

Netzer et al. (2008)

Homburg et al. (2009)

Typical brand choice (marketing mix) model
Long-Term Model

(Customers' long-term value assumed, does address balance)

Johnson and Selnes (2004)

Proposed customer portfolio management model forward 50 years, Youth represent more future automobile purchases than do Adults or Seniors.) Second, information in a vendor's transaction database is, by definition, restricted to that vendor. If one wishes to understand competitors, one must work with a dataset that includes information on competitors' transactions, too. Finally, automobiles have a long purchase cycle, so no automaker is likely to have a database with the number of transactions for each customer that the existing customer portfolio management models require.

\section{Marketing and customer mix variables}

For this application, we use data from BIGresearch's monthly Customer Intentions and Actions Survey (CIA) administered by Prosper Foundation Insight Center, ${ }^{5}$ 2008 through 2011. This data comes from a nationally projectable survey of about 8000 respondents per month on average. Of the approximately 384,000 (8000/month $\times 48$ months) total respondents in the observation period, about 64,000 are expected to have been in the market for a car (assuming that cars are replaced every 6 years as noted in Terech et al., 2009). Of the respondents, 16,067 reported having purchased either a General Motors, Ford, Toyota, or Honda vehicle (about $25 \%$ of the estimated 64,000 CIA respondents expected to be in the market for a car). For each vehicle purchase, we get some marketing information: brand/make; vehicle configuration-type (car, truck, SUV); whether it was new or used; and price paid (BIGresearch's exact question wordings are reported in Web Appendix A). With these data we calculate an automaker's monthly customer mix and we infer different customer types' sensitivities to that automaker's marketing (price, vehicle configuration). In practice, an automaker would have other proprietary and secondary data with which they could enrich the model. However, the BIGresearch data is sufficient to illustrate the proposed model.

\footnotetext{
${ }^{5} 400$ West Wilson Bridge, Suite 200 Worthington, Ohio 43,085.
}

\section{Advertising responsiveness variables}

BIGresearch's biannual Simultaneous Media Usage (SIMM) Survey supplies data that augments marketing information on price and vehicle configuration. Rather than reporting the amount a company spends on advertising or the number of ads a customer has seen, "advertising" indicators that are more typical in the literature, the SIMM survey reports customers' responsiveness to persuasive messages delivered through different media. In SIMM, respondents checked off, for each of nine product categories (including automobiles), those media whose messages would be likely to influence their purchase from that category. For each medium, for each respondent, we record a 1 if the respondent indicated that his or her vehicle purchase was influenced by messages in that medium; 0 otherwise. (The 22 media considered are: word of mouth, magazine, newspaper, TV, article, radio, direct mail, email, internet, billboard, satellite radio, web radio, cable TV, cell video, instant messages, text messages, blogs, game ads, social network, mobile, placement, and yellow pages.)

Two problems arise when we try to link SIMMreported media influence variables with the other marketing predictors and observations of customer mix from CIA. First, the two surveys are fielded with different frequencies, so we must consider the problem of linking SIMM's 6-monthly media influence data to CIA's monthly automobile purchase data. Second, because respondents are not identified in either CIA or SIMM, we cannot directly link the SIMM-reported media influencing a particular respondent's automobile purchase to the CIA-reported automobile purchased by that respondent.

To deal with the first issue, we associate the biannual SIMM (media influence) data collected in a given month (December and June) with (a) the CIA (automobile purchase) data that was collected in that same month and with (b) the CIA data collected in each of the following 5 months. To address the second issue, we merge the CIA and SIMM data sets using statistical data fusion methods (Duan et al., 2012) with demographic profiles 
as fusion variables. (Data fusion details are reported in Web Appendix B.)

\section{Simplifying media}

As one might expect, estimates of the influence of messages delivered through 22 different communication media are correlated with one another. Auto buyers influenced by messages in magazines are also likely to be influenced by messages in newspapers, TV, and radio. Auto buyers influenced by text messages are also likely to be influenced by messages in blogs and game ads. (The matrix of correlations between all pairs of media are reported in Web Appendix C.) If we include all 22 media influence predictors in the proposed customer portfolio management model, resulting multicollinearity would render medium-specific influence coefficients uninterpretable. To address this problem, we factor analyzed medium-specific influence predictors. Varimax rotation revealed two factors with eigenvalues $>1$, representing two collections of media whose influence probabilities tended to move together. Table 3 shows two media influence factors (rotated loadings), which we named Contemporary Media Influence (dominated by Text Messages, Social Network, Blogs, Game Ads, Mobile, Cell Video, Web Radio, Instant Messages, and Satellite Radio) and Conventional Media Influence (dominated by Magazine, TV, Newspaper, Direct Mail, Word-of-Mouth, and Articles).

\section{Model}

\section{Logic underlying the proposed model}

The proposed customer portfolio management model holds that the more the company does to attract a particular type of customer, the bigger will be the proportion of that customer type in the company's customer mix (Godfrey 2006). That is, we assume that a company can target effectively with the instruments in hand. If the company's products, communications and marketing target customers of type $c$, then that company should attract customers of type $c$ more strongly than it attracts other customer types, and consequently, should have a customer mix that includes more type $c$ customers.

The proposed model can be derived from three assumptions. First, we assume that the strength with which the company attracts a customer of type $c$ has both a deterministic component (the influence of the company's marketing on the strengths with which the company attracts $c$ ) and a stochastic component (temporary changes in the strength with which the company attracts $c$, for example, because $c$ is buying a gift or because $c$ just observed a celebrity using the product.)
Table 3 Factor analysis of media influence predictors 2008-2011 $(n=28,918)$

\begin{tabular}{lll}
\hline & Contemporary Media & Conventional Media \\
\hline Text Messages & $\mathbf{0 . 7 1}$ & -0.08 \\
Social Network & $\mathbf{0 . 6 9}$ & -0.13 \\
Blogs & $\mathbf{0 . 7 1}$ & -0.05 \\
Game Ads & $\mathbf{0 . 6 9}$ & -0.02 \\
Mobile & $\mathbf{0 . 6 8}$ & -0.10 \\
Cell Video & $\mathbf{0 . 6 6}$ & -0.04 \\
Web Radio & $\mathbf{0 . 6 6}$ & -0.01 \\
Instant Messages & $\mathbf{0 . 6 6}$ & -0.05 \\
Satellite Radio & $\mathbf{0 . 5 9}$ & 0.09 \\
Magazine & 0.07 & $\mathbf{0 . 6 7}$ \\
TV & 0.04 & $\mathbf{0 . 6 1}$ \\
Newspaper & 0.04 & $\mathbf{0 . 4 8}$ \\
Direct Mail & 0.01 & $\mathbf{0 . 4 5}$ \\
Word of Mouth & -0.15 & $\mathbf{0 . 5 5}$ \\
Article & -0.39 & $\mathbf{0 . 6 7}$ \\
Email & 0.28 & 0.45 \\
Radio & 0.25 & 0.46 \\
Placement & 0.46 & 0.24 \\
Billboard & 0.48 & 0.27 \\
Yellow Pages & 0.35 & 0.12 \\
Internet & 0.50 & 0.35 \\
Cable TV & 0.45 & 0.38 \\
Eigenvalue & 6.82 & 2.24 \\
\hline & &
\end{tabular}

Second, we assume that the company makes a particular sale to the customer type that it attracts most strongly at the time of that sale. This can be thought of as suggesting that a strongly attracted customer is likely to go out of his/her way to be sure that he/she makes the purchase and that a weakly attracted customer is not likely to put in the effort needed to make the purchase.

The final assumption in the proposed customer portfolio management model is that the random component of the strength with which the company attracts customer type $c$ at the time of a specific transaction has a double-exponential (Gumbel Type II extreme value) distribution. ${ }^{6}$ McFadden

\footnotetext{
${ }^{6}$ The concept of attraction as a latent variable with a company's customer mix being a normalized function of that latent variable is consistent with many models of natural phenomena in marketing. In fact, McFadden (1974) began by asserting equation (1)'s functional form because of the intuitive appeal of Luce's (1959) choice axiom (which is defined by this functional form). Given the functional form desired for his model, McFadden (1974) reports that he worked backward to determine that this function form would result if one assumed that the random component has a double exponential (Gumble Type II extreme value) distribution. Hence he proposed that distributional assumption, knowing that it would yield the functional form in equation (1) which he desired for his model.
} 
(1974) has shown that these three assumptions imply that the probability that the company's $i^{\text {th }}$ sale in period $t$ is to a customer of type $c$ can be interpreted as c's share in the company's customer mix $^{7}$ and is estimated by:

$\exp$ (strength with which company attracts $c$ for its ith sale in period $t$ )

$\overline{\sum_{\text {customer types c }} \exp \left(\text { strength with which company attracts } c^{\prime} \text { for its ith sale in period } t\right)}$

We elaborate on the model structure presented in eq. (1) by operationalizing "deterministic component of the strength with which company attracts $c$ " $=A_{c}$. (For a complete statement of the model, see Web Appendix E.) Let:

$C T_{c}=$ Customer type $c$ dummy variable.

$=1$, if customer purchasing a General Motors vehicle is of type c; 0 , otherwise.

$X_{r}=$ the value of the $r^{\text {th }}$ predictor (that is constant across customers) for the General Motors' vehicle purchased.

$M_{F}=$ value of the $F^{\text {th }}$ media influence factor (that differs across customers) for the customer purchasing the General Motors' vehicle

$$
\begin{aligned}
& A_{c}=\sum_{\text {customer topes }} b_{c} C T_{c}+\sum_{r=\text { predictor }} \sum_{\text {c=customer types }} g_{r c} C T_{c} X_{r} \\
& +\sum_{F=\text { Media Influence Factor }} h_{F} M_{F}
\end{aligned}
$$

\section{Model coefficients}

As in Netzer et al.'s (2008) model, most predictors in the proposed customer portfolio management model are customer type-specific.

Customer type-specific intercepts We include dummy variables, $C T_{c}$ to indicate the type of customer making a specific purchase of a General Motors vehicle. As did Netzer et al. (2008), we interpret coefficients of these dummy variables to be "customer type specific intercepts." ${ }^{8}$ We designate a "reference" customer type (Youth) for which no intercept is estimated and denote the customer type $c$-specific intercept as $b_{c}$. Following the tradition of interpreting brand-specific intercepts in choice models as "brand equity" (Srinivasan 1979; Kamakura and Russell, 1993; Park and Srinivasan, 1994; Srinivasan et al., 2005; Sriram et al., 2007) we interpret customer type-specific intercepts $\left(b_{c}\right)$ as "customer type equity," the strength with which General Motors attracts customers of type $c$ based on General Motors' basic positioning. All else equal, each customer

\footnotetext{
${ }^{8}$ Netzer et al. (2008) refer to customer types as "states" and refer to customer type-specific intercepts as "state dependent intercepts."
}

type should be represented in General Motors' customer mix in proportion to these "customer type equities."

Customer type-specific coefficients for marketing predictors that are constant aross customer types We propose customer type-specific coefficients for marketing predictors and economic environment predictors. These marketing predictors include price tier (low-price, mid-price and high-price), vehicle specification - type (new vs. used), and fuel efficiency (efficient vs. inefficient). We also include a recession predictor (before, during, or after ${ }^{9}$ ). Note that the characterization of a particular General Motors vehicle is the same for all customers. If a particular vehicle is a mid-price, used, fuel efficient vehicle sold during the recession-that vehicle has that configuration for every customer considering its purchase during the recession.

These constant-across-customer-types predictors have been discretized. The variable level which is not indicated by a dummy will be referred to as the reference level. The first column of Table 4 reports, for each of these variables, the percentage of the 6784 reported General Motors' vehicles purchased in our data between 2008 and 2011 corresponding to each level of each discretized predictor. (Reference level is indicated as “((r)")).

Coefficients of these constant-across-customer-types, discretized predictors $\left(g_{r c}\right)$ indicate the way General Motors' customer mix can be expected to differ for different vehicle configurations or different states of the economy. For example, if the Adult-specific coefficient for the mid-price tier predictor is less than the Senior-specific coefficient for the mid-

\footnotetext{
${ }^{7}$ The structure of the proposed customer portfolio management model is parallel to the structure of the more familiar brand choice model. This parallel might make one wonder whether it would not be possible to achieve equivalent customer mix insights using a brand choice approach. Web Appendix D shows that customer mix insights drawn from brand choice models are inferior to those derived directly from the proposed customer portfolio management model.

${ }^{9}$ Our data stretch from the beginning of 2008 , before the 2008 financialinstitution-failure-induced recession, until 2011, well after that recession ended. Because an economic recession effects some customer types more powerfully than others, we expect the recession to influence the strength with which General Motors is able to attract different customer types. Following the National Bureau of Economic Research definition, the recession began September 2008 when GDP fell and Unemployment Rate rose dramatically and ended after December 2009 when the economy returned to conventional levels of GDP and Unemployment.
} 
Table 4 Descriptive statistics for predictors in proposed customer portfolio management model for General Motors 2008-2011 ( $\mathrm{n}=6784)$

\begin{tabular}{|c|c|c|}
\hline & & General Motors \\
\hline \multirow[t]{3}{*}{ Customer Type } & Youth $^{(\mathrm{r})}(16-34)$ & $31 \%$ \\
\hline & Adult $(35-54)$ & $35 \%$ \\
\hline & Senior $(>55)$ & $34 \%$ \\
\hline \multirow[t]{3}{*}{ Price Tier } & Low-price $^{(\mathrm{r})}(<\$ 15 \mathrm{~K})$ & $41 \%$ \\
\hline & Mid-price $(\$ 15 \mathrm{~K}-\$ 30 \mathrm{~K})$ & $44 \%$ \\
\hline & High-price (> \$30 k) & $15 \%$ \\
\hline \multirow[t]{2}{*}{ New/Used indicator } & $\mathrm{New}^{(\mathrm{r})}$ & $48 \%$ \\
\hline & Used & $52 \%$ \\
\hline \multirow[t]{2}{*}{ Fuel Efficiency } & Fuel Efficient ${ }^{(\mathrm{r})}$ (car) & $67 \%$ \\
\hline & Fuel Inefficient (SUV,trucks) & $33 \%$ \\
\hline \multirow[t]{3}{*}{ Recession } & Before $^{(\mathrm{r})}(1 / 08-8 / 08)$ & $16 \%$ \\
\hline & During $(9 / 08-12 / 09)$ & $30 \%$ \\
\hline & After $(1 / 10-12 / 10)$ & $54 \%$ \\
\hline \multicolumn{2}{|c|}{ Contemporary Media Influence (average) } & -.16 \\
\hline \multicolumn{2}{|c|}{ Word of Mouth Influence (average) } & .31 \\
\hline \multicolumn{2}{|c|}{ Conventional Media Influence (average) } & .08 \\
\hline
\end{tabular}

${ }^{(r)}$ Reference level for discretized variable

price tier predictor and if both the Adult-specific and the Senior-specific coefficients for mid-price tier are significant and positive, then (all else equal) General Motors should expect the customer mix for its mid-priced vehicles to have more Seniors than Adults and more Adults than Youth.

\section{Coefficients for predictors that vary across customer types} Because the level of a media influence factor differs across customers (which implies that it differs across customer types), we need only a single predictor for each media influence factor rather than several customer type-specific predictors as just proposed for those predictors that are constant across customer types. The coefficient of that single predictor for a media influence factor $F, h_{F}$, can be interpreted as reporting the effectiveness of General Motors' messages in media influence factor $F$. For example, a positive, significant coefficient for the "Conventional Media" predictor would imply a big boost to the strength with which General Motors attracts a potential customer who is highly influenced by conventional media and very little change to the strength with which General Motors attracts a potential customer who is indifferent to messages delivered through conventional media.

\section{Results}

Letting $p_{c^{*} i t}$ represent the proposed customer portfolio management model-determined probability that the $i^{\text {th }}$ purchase of a General Motors vehicle in period $t$ was made by customer type $c^{*}$ that actually made the $i^{\text {th }}$ purchase in period $t$, we estimate parameters of the proposed customer portfolio management model (with $I_{t}$ denoting a purchase of a General Motors vehicle in period $t$ and $T$ periods) by maximizing the likelihood function, $\prod_{t=1}^{T} \prod_{i=1}^{I_{t}} p_{c^{*} i t}$, made up of one term for each of the 6784 CIA respondents who reported having purchased a General Motors vehicle between January 2008 and December 2011. Table 5 reports the estimated coefficients for General Motors' proposed attraction-based customer portfolio management model.

The first row of Table 5 reports estimated values for General Motors' customer type-specific intercepts. These intercepts are interpreted relative to the reference level for customer type, Youth. Hence, the significant, positive customer type-specific intercepts for Adults and Seniors (coefficient of Adults $=.38$, coefficient of Seniors $=.54, p<$ .001 for both), implies that, in the reference case (i.e. when other predictors are at their reference levels: Low-price, new, fuel efficient vehicles; before recession; average media influence), General Motors attracts Adults and Seniors more powerfully than it attracts Youth. One can think of these customer type-specific intercepts (when combined with the impact of media influence variables at their average levels) as defining General Motors' "baseline" customer mix, that is, the mix of Youth, Adults, and Seniors that General Motors could expect for the reference case. Applying parameter estimates from Table 5 and average values for media influence variables from Table 4 , that baseline customer mix is expected to be $22 \%$ Youth, $36 \%$ Adults, and $42 \%$ Seniors. (In what follows we will summarize customer mix with a three-element vector representing \% Youth, \% Adult, and \% Seniors. Using that convention, General Motors' expected baseline customer mix is represented as $22 \%, 36 \%, 42 \%$.)

The remaining coefficients in the proposed customer portfolio management model for General Motors (Table 5) report the way in which the strength with which General Motors' attracts Youth, Adults and Seniors shifts for different vehicle configurations. Consider Price Tier. Both General Motors' mid- and high-price vehicles attract Adults and Seniors more strongly than do General Motors' reference level, low-price vehicles (coefficient of midprice for Adults $=.20$, coefficient of mid-priced for Seniors $=.62$, coefficient of high-priced for Adults $=.59$, coefficient of high-priced for Seniors $=1.35, p<.001$ for all except mid-price for Adults which is significant at $p<$ .01). If all predictors other than Customer Type and Price Tier were at reference levels, General Motors low-price vehicles should expect the baseline customer mix. Their mid-price vehicles should expect a customer mix of $(15 \%, 31 \%, 54 \%)$, and their high-price vehicles should expect a customer mix of $(9 \%, 26 \%, 65 \%)$. 
Table 5 Proposed customer portfolio management model for General Motors, 2008-2011 ( $n=6784$ )

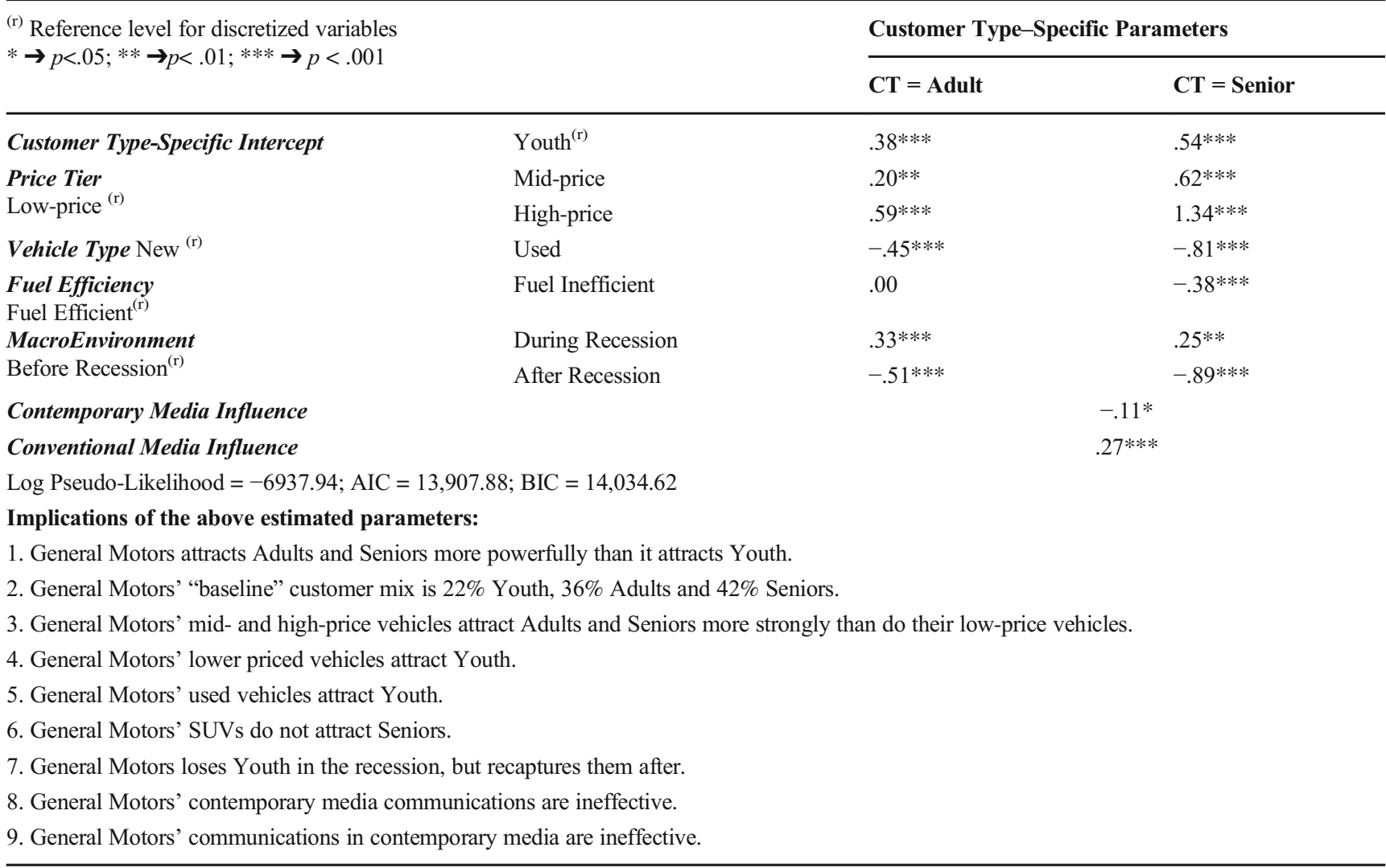

In a similar way, coefficients of the Vehicle Type (New vs. Used) predictors, indicate that General Motors' used vehicles attract Adults and Seniors less strongly than do General Motors' reference level, new vehicles resulting in an expected customer mix for General Motors' used vehicles of $(35 \%$, $36 \%, 29 \%)$. The coefficients for vehicle design characteristic Fuel Efficiency indicate that General Motors' fuel inefficient vehicles attract Seniors less powerfully than do General Motors' reference level, fuel efficient vehicles resulting in an expected customer mix for General Motors' fuel inefficient vehicles of $(26 \%, 42 \%, 33 \%)$.

The coefficients of During and After Recession indicate that the strength with which General Motors attracted Adults and Seniors rose During Recession but then fell After Recession, resulting in an expected customer mix of $(18 \%$, $40 \%, 42 \%$ ) During Recession and an expected customer mix of $(37 \%, 35 \%, 28 \%)$ After Recession.

In contrast to the constant-across-customer-type predictors just discussed, media influence factor predictors differ across customers and so do not require customer type-specific coefficients. To consider the impact of Conventional Media Influence and Contemporary Media Influence, we hold all predictors other than Customer Type and the particular media influence under consideration at reference levels. We contrast the baseline customer mix (expected when the considered media influence predictor is at its average value for each customer type) to the customer mix expected when that media influence predictor, for one of the customer types, increases to the 90th percentile of the values it takes on. (Average values and 90th percentile values for each media influence factor, for each customer type, are reported in Appendix B Table 8.)

The significant negative coefficient for Contemporary Media Influence reported in Table 5 (coefficient of Contemporary Media Influence $=-.11, p<.05$ ) suggests that General Motors' communications in Contemporary Media are ineffective or even counter-productive. The more likely it is that a potential vehicle purchaser is influenced by messages in Contemporary Media, the lower is the strength with which General Motors attracts that potential purchaser.

Taken together, these results are consistent with the intuition that General Motors is short on young purchasers and that this problem gets worse for General Motors when the economy falls and for young purchasers who are influenced by Contemporary Media. General Motors most strongly attracts young purchasers with used, low-priced, and fuel inefficient vehicles. These, and other implications of estimated 
parameters of the automakers are summarized at the bottom of Table 5. Expected customer mixes associated with different levels of each predictor can be found in Appendix B Table 8.

\section{Proposed customer portfolio management model for multiple automakers}

Unlike earlier customer portfolio management models that were tied to a particular vendor's transaction database, we estimate the proposed customer portfolio management model with data that includes purchases of all automakers' vehicles. With that data, we can simultaneously estimate the proposed customer portfolio management model for multiple competing automakers by allowing estimated coefficients to be automaker-specific. Taking General Motors as the reference automaker, we define the deterministic component of the strength with which automaker $d$ attracts customers of type $c$ at the time of the $i^{\text {th }}$ purchase of a vehicle from that automaker in period $t$ as a function of automaker-specific, customer type-specific intercepts; automaker-specific, customer type-specific coefficients for discretized marketing predictors that are constant across all customer types; and automaker-specific media influence predictors. (For the technical specification of the multi-automaker model, including GM, see Web Appendix E.)

Table 6 reports coefficients estimated for the proposed customer portfolio management model for multiple automakers. In addition to reporting effects relative to predictors' reference levels as did the single automaker model reported earlier, this multiple-automaker model's coefficients also report automaker-specific effects relative to effects for the reference automaker, General Motors.

Notice, first, that estimates for the reference automaker, General Motors, in Table 6's multi-automaker customer portfolio management model, are equal to General Motors' estimated parameters in the proposed single-automaker customer portfolio management model reported in Table 5. In this multi-automaker formulation, every predictor has automaker-specific coefficients, so we get, essentially, automaker-specific models. The benefit of this formulation over separately estimating models for each automaker is that the coefficients of General Motors' competitors' models are defined relative to the coefficients of General Motors' model. That is, the coefficient of a particular predictor for a competitor in the multi-automaker formulation is only significant if the influence of that predictor on the competitor's customer mix is significantly different from the influence of that predictor on General Motors' customer mix. With this multiautomaker model, then, General Motors can identify those customer mix shaping forces that work significantly differently for other automakers, deepening General Motors' competitive insight.

Consider the block of coefficients reporting Customer Type-Specific Intercepts in Table 6. Just as in Table 5, Table 6 tells us that General Motors attracts Adults and Seniors more strongly than it attracts Youth. The fact that, for Ford and Toyota, neither the Adult or Senior coefficients is statistically significant, implies that the basic strength with which Ford and Toyota attract Adults and Seniors is not statistically distinguishable from the basic strength with which General Motors attracts Adults and Seniors. The basic strength with which Honda attracts different customer types, on the other hand, is quite different. Adding Honda's significant negative coefficients for Adults and Seniors to General Motors' significant positive coefficients, suggests that Honda attracts Adults and Seniors less strongly than it attracts Youth. Apparently Honda's basic positioning more effectively attracts Youth than do the basic positionings for General Motors, Ford, and Toyota.

A full interpretation of estimated coefficients of the multiautomaker model can be found in Web Appendix F. The implications of those estimated parameters are summarized at the bottom of Table 6 .

In summary, General Motors' and Toyota's baseline customer mixes are relatively low in Youth while Ford's and Honda's baseline customer mixes include higher proportions of Youth. The strength with which Honda attracts Youth is rooted in its basic positioning. The strength with which Ford attracts Youth is rooted in Ford's distinctive ability to capitalize on the growing influence of Contemporary Media on Youth.

Honda's appeal for Youth in the baseline case is echoed by Honda's heightened ability to draw Youth back into the franchise after the recession. Also distinctive, Honda most strongly attracts Adults (while other automakers most strongly attract Seniors) with high priced vehicles and Honda most strongly attracts Seniors (while General Motors and Ford most strongly attract Youth) with fuel inefficient vehicles. Toyota on the other hand, distinctively attracts Adults with its fuel inefficient vehicles.

\section{Discussion, limitations, and directions for future research}

In the introduction, we characterized customer relationship management models and most customer portfolio management models as being "short term" in the sense that those models are designed to increase return from current customers next period and they consider only current customers. The proposed customer portfolio management model is designed to address a different problem - the problem of keeping the 
Table 6 Proposed customer portfolio management model for General Motors (reference automaker), Ford, Honda, and Toyota, 2008-2011 ( $n=16,067$ )

(r) Reference level for discretized variables

Customer Type CT=Adults

Specific Parameters $C T=$ Seniors

$* \rightarrow \mathrm{p}<.05 ; * * \rightarrow \mathrm{p}<.01 ; * * * \rightarrow \mathrm{p}<.001$

\begin{tabular}{|c|c|c|c|}
\hline \multirow[t]{4}{*}{ Customer Type-Specific Constant (Youth $\left.{ }^{(r)}\right)$} & General Motors $^{(r)}$ & $.38 * * *$ & $.54 * * *$ \\
\hline & Ford & -.09 & -.24 \\
\hline & Honda & $-.89 * * *$ & $-1.17 * * *$ \\
\hline & Toyota & -.16 & $-.49 * *$ \\
\hline \multirow[t]{8}{*}{ Price Tier (Low-price ${ }^{(\mathrm{r})}$ ) } & General Motors $^{(\mathrm{r})}$ Mid-price & $.20 * *$ & $.62 * * *$ \\
\hline & General Motors $^{(\mathrm{r})}$ Hi-price & $.59 * * *$ & $1.34 * * *$ \\
\hline & Ford Mid-price & -.06 & -.11 \\
\hline & Ford High-price & .16 & -.06 \\
\hline & Honda Mid Price & .17 & .10 \\
\hline & Honda High-price & $.68 * * *$ & $-.53 *$ \\
\hline & Toyota Mid-price & .07 & .01 \\
\hline & Toyota High-price & -.22 & -.20 \\
\hline \multirow[t]{4}{*}{ Vehicle Type $\left(\mathrm{New}^{(\mathrm{r})}\right)$} & General Motors $^{(\mathrm{r})}$ Used & $-.45 * * *$ & $-.81 * * *$ \\
\hline & Ford Used & .17 & .05 \\
\hline & Honda Used & -.00 & -.29 \\
\hline & Toyota Used & -.20 & -.11 \\
\hline \multirow{4}{*}{$\begin{array}{l}\text { Fuel Efficiency } \\
\text { Fuel Efficient }{ }^{(\mathrm{r})}\end{array}$} & General Motors $^{(\mathrm{r})}$ Ineff. & .00 & $-.38 * * *$ \\
\hline & Ford Inefficient & $.21 * *$ & $.57 * * *$ \\
\hline & Honda Inefficient & .12 & $.98 * * *$ \\
\hline & Toyota Inefficient & $.32 * *$ & .19 \\
\hline \multirow{8}{*}{$\begin{array}{l}\text { MacroEnvironment } \\
\text { Before-Recession }^{(\mathrm{r})}\end{array}$} & General Motors $^{(r)}$ During & $.33 * * *$ & $.25^{* *}$ \\
\hline & After & $-.51 * * *$ & $-.89 * * *$ \\
\hline & Ford During Recession & -.13 & .15 \\
\hline & After Recession & $.34 * *$ & $.57 * * *$ \\
\hline & Honda During Recession & -.21 & .08 \\
\hline & After Recession & $-.44 * *$ & -.31 \\
\hline & Toyota During Recession & $-.33 *$ & .03 \\
\hline & After Recession & -.20 & .13 \\
\hline
\end{tabular}

Contemp. Med. Infl.

Convent. Med. Infl.
General Motors $^{(r)}=-.11 * ;$ Ford $=.29 * * * ;$ Honda $=-.59 * * * ;$ Toyota $=-.32 * * *$

General Motors ${ }^{(r)}=.27 * * * ;$ Ford $=-.15^{* * *} ;$ Honda $=.43 * * * ;$ Toyota $=.31 * * *$

Number of Observations $=16,067 ;$ Log Likelihood $=-16,292.76 ;$ Pseudo R-Square $=.494$

\section{Implications of Above Estimated Parameters}

1. General Motors, Ford, and Toyota attract Adults and Seniors; Honda, Youth

2. General Motors', Honda's, and Toyota's communications in contemporary media are ineffective

3. Ford and Honda attract Youth more than General Motors and Toyota do.

4. Honda's positioning attracts Youth.

5. Ford attracts Youth with communications in contemporary media.

6. Ford is the only automaker with effective communications in contemporary media

7. General Motors', Ford's, and Toyota's high-priced vehicles attract Seniors.

8. Honda's high-priced vehicles attract Adults.

9. Honda's fuel inefficient (i.e., SUV) vehicles attract Seniors.

10. Toyota's fuel inefficient (i.e., SUV) vehicles attract Adults.

11. The recession's impact on customer mix is the same for all four automakers.

12. After the recession, Honda recaptured Youth more effectively.

company viable in the long term. If a company focused only on increasing the value of current customers it would eventually go out of business when those valuable current customers all died. Of course, no company would do this. 
Instead their short-term models would be nested within a longer-term perspective on customer management.

That longer term perspective requires that the company consider balance in its mix of customers. As in the examples discussed, Harley seeks balance across its short-term-morevaluable loyal customers and short-term-less-valuable entrylevel customers. Seventh Generation seeks balance across "high-involved sustainable consumption customers" and "low-involved sustainable consumption customers" by avoiding marketing interventions which are effective with low-involved customers but which are also alienating to high-involved customers.

We illustrated the use of this model in the automotive industry with a focus on General Motors. We considered Youth, Adults, and Seniors as customer types and assumed that Adults and Seniors are more profitable in the short term. However, given the level of brand loyalty in the automotive industry (Welsh 2013), General Motors needs to constantly attract entry-level Youth (despite Youth's lower short-term value) in order to survive in the long term. Estimated parameters of the General Motors customer portfolio management model indicate that General Motors could increase the strength with which it attracts Youth by focusing product development and communications on lower-priced vehicle lines and on fuel-inefficient SUVs and trucks. Interestingly, General Motors' product launches subsequent to the end of our data collection period (i.e., after 2011) have been consistent with these recommendations. As mentioned in the section "Empirical example: General Motors and the Aauto Iindustry," General Motors did, in fact, launch a number of products targeted to Youth that were consistent with recommendations based on estimated model parameters. General Motors launched Encore for Youth in 2013, their earlier launch of Volt for Youth began failing in 2013, and in 2015 they launched two trucks (Chevrolet Colorado and GMC Canyon) aimed at Youth. We also note that re-estimating models with data from 2016 to 2019 shows that General Motors attempts to re-balance its customer-portfolio were effective. In particular, General Motors' baseline customer mix shifted from (22\% Youth, $36 \%$ Adults, $42 \%$ Seniors) for 2007-2011 to (33\% Youth, $26 \%$ Adults, $41 \%$ Seniors) for 2016-2019. (The results for the 2016-2019 model is reported in the Web Appendix G.)

Estimated parameters of the Four-Automaker customer portfolio management model indicate that General Motors' basic positioning contributes less than does Honda's basic positioning to the strength with which Youth are attracted. Further, for those Youth whose auto purchases are swayed by messages in Contemporary Media, the more strongly those Youth are swayed than Adult and Seniors, the more strongly Ford attracts them and the less strongly General Motors attracts them.
We note that the proposed model is a measuring instrument, not an optimization model. The proposed model cannot tell a company when to switch from focusing on currentlyvaluable loyal customers to begin focusing on less valuable entry-level customers that are vital for survival. The proposed customer portfolio management model provides a tool to help harmonize the two. If a company knows, for each marketing intervention, the influence of that intervention on each important customer type, then the company can assemble a portfolio of marketing interventions, some more strongly attracting currently valuable customers and others attracting valuable-inthe-future customers, such that the collection of marketing interventions bring balance to the customer mix.

Such a long-term model should be complemented with short-term CRM or CPM models to fine-tune offerings to current customers in a way that constantly increases next period's sales to those customers under the constraint that proposed interventions do not change the mix of customers a company attracts in a way that imperils the company's longterm survival.

\section{Limitations}

This study has limitations that need to be acknowledged. First, we note that the model is based on three assumptions and those assumptions might be violated. The model first assumes that the strength with which a company attracts a customer has both a deterministic and a stochastic component. If either component were missing the problem would be uninteresting. (The absence of a deterministic component would imply that marketing has no influence on the strength with which a company attracts different customer types. The absence of a stochastic component would make algebra sufficient for determining marketing's influence.) Second, we assume that the company makes a sale to the most strongly attracted customer. This assumption might be violated in times of extreme shortage, e.g., early coronavirus-driven hoarding. However, in normal circumstances we would expect the strength with which a good attracts a customer to influence the probability that the good is purchased by that customer.

Finally, the assumption that the stochastic component of attraction strength has a double exponential distribution was made in order to yield the intuitive functional form of eq. (1). This functional form is known to possess a property which we paraphrase as "independence of irrelevant customer types." That is, if a new customer type were introduced into the model, the model form suggests that it should "steal" customer share proportionally from each of the existing customer types. This assumption would be violated if introducing a new customer type into the customer mix actually reduced the strength with which the company attracted an existing customer type. In this case, the newly introduced customer type would disproportionately reduce the customer-share for that existing 
customer type. In such a case, the functional form of eq. (1) would no longer be appropriate and so it would no longer be true that the customer mix model form hinged on the assumption that the stochastic component of attraction strength has a double exponential distribution.

In addition, we estimated the proposed customer portfolio management model for only one long purchase cycle industry. While we assert that the model would perform well for frequently purchased goods and for business-to-business goods, we have not demonstrated that fact. It is also the case that we estimated the model at the company level and that may mask important dynamics at the brand level. We consider only one set of customer types for the proposed customer portfolio management model and have not demonstrated efficacy for alternative definitions for customer type.

We included one set of variables related to marketing, but other marketing variables might be considered. Perhaps one could draw additional insight if one considered the many features examined by JD Power (exterior, interior, features/controls/displays, audio/entertainment/navigation systems, seats, climate controls, powertrain, and driving experience). Related, we have not considered national marketing events run by auto makers because, like customer relationship management studies, we do not have access to marketing managers' systematic record keeping on the nature and timing of events. Finally, there may be other forces in the macro environment (e.g., coronavirus) that influence a company's ability to attract different customer types.

We note that though we have panel data from surveys, we do not have experimental panel data and so cannot be assured that we have identified causal relationships. We do link changes in a company's marketing to changes observed in customer mix, but we cannot rule out the possibility that some third factor caused both the change in marketing and the change in customer mix.

We are interpreting model coefficients, not customers' testimony. To be fully confident that we understand the forces that drive the strength with which a particular customer type is attracted, it would be good to have confirming information from those customer types.

\section{Directions for future research}

In addition to addressing the limitations just listed, future research could explore the antecedents of media influence coefficients. Those coefficients might be driven by differences in a company's communication budget allocation systems, ${ }^{10}$ differences in its messages (Guitart et al., 2018), differences by country of origin (Hsieh et al., 2004), the match between the message's narrative person and the brand's image (Chang

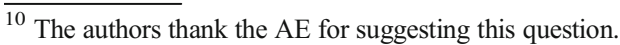

et al., 2019), or differences in the company's brand portfolio (Kirca et al., 2019).

Future research could also explore manufacturer-specific constants in the multi-manufacturer model. Those constants represent something like "customer type equity," related to a company's fundamental position's ability to attract that customer type. Interpreting these coefficients in this way is analogous to interpreting brand-specific constants as "brand equity" in conjoint studies (Srinivasan 1979; Park and Srinivasan, 1994; Srinivasan et al., 2005) and choice models (Kamakura and Russell, 1993; Sriram et al., 2007). Investigation of the antecedents of "customer type equity" analogous to Datta et al. (2017) investigation of the antecedents of "brand equity" could also prove fruitful for understanding positioning strategies.

Like Reimann et al. (2010), one could relate estimated model parameters to the strength of the associated company's customer management efforts. Alternatively, one could add a model component to account for the recapture of "lost" customers. Pick et al. (2016) tell us that, over time, a defector's mindset shifts, changing the nature of effective recovery efforts.

Finally, Jayachandran et al. (2004) confirm that customer insight (like that provided by the proposed customer portfolio management model) is critical for the long-term sustainability of the company's competitive advantage. Not only does that insight enhance the strength with which the company attracts target customers, but it also reduces internal-to-the-company uncertainty. If it reduces the perceived riskiness of a proposal, it can improve the likelihood of the proposal being funded internally. Future research should look for such a link.

In summary, it is not always sufficient to understand the link between a company's marketing and its sales. A company needs to know to whom the sales are made in order to balance in its customer mix so it can thrive in both the short and long term. To achieve that balance, the company needs to understand the link between its marketing and the strength with which it attracts different customer types, some more valuable in the short term, others less valuable in the short term but critical for survival in the long term. Knowing, for many marketing interventions, the influence of each marketing intervention on the strength with which different customer types are attracted, a company can cobble together a collection of marketing interventions which, collectively, help the company achieve a customer mix which yields profit in the short term while ensuring survival in the long term.

Supplementary Information The online version contains supplementary material available at https://doi.org/10.1007/s11747-020-00765-9.

Acknowledgments The authors wish to thank Prosper Foundation Insight Center (400 West Wilson Bridge, Suite 200, Worthington, Ohio 43085) for providing the data used in this paper. They also thank The McCombs School of Business, IE Business School and EMLV for supporting this research. 


\section{Appendix A}

Table 7 Media influence factor variables used in calculating expected customer mixes

\begin{tabular}{|c|c|c|c|c|c|c|c|c|c|c|c|c|}
\hline & \multicolumn{3}{|c|}{ General Motors } & \multicolumn{3}{|l|}{ Ford } & \multicolumn{3}{|l|}{ Honda } & \multicolumn{3}{|c|}{ Toyota } \\
\hline & Youth & Adult & Seniors & Youth & Adult & Seniors & Youth & Adult & Seniors & Youth & Adult & Seniors \\
\hline \multicolumn{13}{|c|}{ Contemporary Media Influence } \\
\hline 10th Percentile & -.51 & -.98 & -1.10 & -.23 & -.78 & -1.04 & -.65 & -1.03 & -1.15 & -.57 & -.99 & -1.13 \\
\hline Overall Average & .74 & -.36 & -.76 & 1.17 & -.01 & -.56 & .54 & -.48 & -.85 & .61 & -.41 & -.81 \\
\hline 90th Percentile & 2.16 & .45 & -.29 & 2.46 & 1.00 & -.13 & 1.82 & .20 & -.44 & 1.83 & .31 & -.34 \\
\hline \multicolumn{13}{|c|}{ Conventional Media Influence } \\
\hline 10th Percentile & -1.08 & -1.01 & -1.42 & -1.19 & -1.26 & -1.41 & -1.04 & -1.01 & -1.31 & -1.07 & -.83 & -1.36 \\
\hline Overall Average & .10 & .20 & -.04 & .02 & -.01 & -.25 & .22 & .32 & .17 & .21 & .30 & .06 \\
\hline 90th Percentile & 1.25 & 1.61 & 1.21 & 1.07 & 1.29 & 1.10 & 1.47 & 1.90 & 1.28 & 1.47 & 1.80 & 1.28 \\
\hline
\end{tabular}

(Overall Average = average value of media influence factor for all customers of a given customer type buying a vehicle from the column-head automaker.

10th Percentile $=$ the tenth percentile value of the distribution of the media influence factor for all customers of a given customer type buying a vehicle from the column-head automaker).

90th Percentile $=$ the ninetieth percentile value of the distribution of the medial influence factor for all customers of a given customer type buying a vehicle from the column-head automaker)

\section{Appendix B}

Table 8 Expected impact of marketing predictor variables on an automaker's customer mixes

\begin{tabular}{|c|c|c|c|c|}
\hline & General Motors & Ford & Honda & Toyota \\
\hline \multicolumn{5}{|l|}{ BASELINE } \\
\hline $\begin{array}{l}\text { (low price, new, fuel efficient; before } \\
\text { recession; average media influence) }\end{array}$ & $(22 \%, 36 \%, 42 \%)$ & $(38 \%, 35 \%, 27 \%)$ & $(46 \%, 29 \%, 25 \%)$ & $(35 \%, 37 \%, 28 \%)$ \\
\hline Mid-price & $(15 \%, 31 \%, 54 \%)$ & $(40 \%, 35 \%, 25 \%)$ & $(43 \%, 31 \%, 26 \%)$ & $(34 \%, 38 \%, 28 \%)$ \\
\hline High-price & $(9 \%, 26 \%, 65 \%)$ & $(37 \%, 39 \%, 24 \%)$ & $(39 \%, 48 \%, 13 \%)$ & $(40 \%, 34 \%, 26 \%)$ \\
\hline Used & $(35 \%, 36 \%, 29 \%)$ & $(36 \%, 38 \%, 26 \%)$ & $(49 \%, 31 \%, 20 \%)$ & $(38 \%, 34 \%, 28 \%)$ \\
\hline Fuel Inefficient & $(26 \%, 42 \%, 32 \%)$ & $(30 \%, 35 \%, 35 \%)$ & $(32 \%, 22 \%, 46 \%)$ & $(29 \%, 43 \%, 28 \%)$ \\
\hline During Recession & $(18 \%, 40 \%, 42 \%)$ & $(38 \%, 31 \%, 31 \%)$ & $(48 \%, 24 \%, 28 \%)$ & $(38 \%, 29 \%, 33 \%)$ \\
\hline After Recession & $(37 \%, 35 \%, 28 \%)$ & $(28 \%, 37 \%, 35 \%)$ & $(55 \%, 23 \%, 22 \%)$ & $(36 \%, 31 \%, 33 \%)$ \\
\hline \multicolumn{5}{|l|}{ Contemporary Media } \\
\hline Youth & $(22 \%, 37 \%, 41 \%)$ & $(43 \%, 31 \%, 26 \%)$ & $(40 \%, 34 \%, 26 \%)$ & $(31 \%, 40 \%, 29 \%)$ \\
\hline Adult & $(23 \%, 34 \%, 43 \%)$ & $(34 \%, 42 \%, 24 \%)$ & $(51 \%, 21 \%, 28 \%)$ & $(38 \%, 32 \%, 30 \%)$ \\
\hline Senior & $(23 \%, 37 \%, 40 \%)$ & $(37 \%, 34 \%, 29 \%)$ & $(49 \%, 30 \%, 21 \%)$ & $(36 \%, 39 \%, 25 \%)$ \\
\hline \multicolumn{5}{|l|}{ Conventional Media } \\
\hline Youth & $(29 \%, 34 \%, 37 \%)$ & $(34 \%, 38 \%, 28 \%)$ & $(61 \%, 21 \%, 18 \%)$ & $(44 \%, 33 \%, 23 \%)$ \\
\hline Adult & $(19 \%, 45 \%, 36 \%)$ & $(41 \%, 31 \%, 28 \%)$ & $(36 \%, 44 \%, 20 \%)$ & $(29 \%, 48 \%, 23 \%)$ \\
\hline Senior & $(19 \%, 31 \%, 50 \%)$ & $(40 \%, 37 \%, 23 \%)$ & $(40 \%, 25 \%, 35 \%)$ & $(31 \%, 33 \%, 36 \%) f$ \\
\hline
\end{tabular}

Table entries represent customer mix. First element in vector is $\%$ of customer mix made up of Youth; second element, \% made up of Adults; third element, \% made up of Seniors.

Each row in this table represents a re-calculated expected customer mix for the situation in which all predictors except that listed in row head are at reference levels.

For each media influence variable, for each customer type, entry represents expected customer mix when row-head customer type's value for that medium goes from the customer type-specific reference level to the customer type-specific maximum monthly average value. 


\section{References}

Berger, J., \& Ward, M. (2010). Subtle Signals of Inconspicuous Consumption. Journal of Consumer Research, 37(4), 555-569.

Brooks, R. (1999), Alienating Customers Isn't Always a Bad Idea, Many Firms Discover. Wall Street Journal, A1, A12 (January 7).

Chang, Y., Li, Y., Yan, J., \& Kumar, V. (2019). Getting more likes: the impact of narrative person and brand image on customer-brand interactions. Journal of the Academy of Marketing Science, 47, 10271045.

Datta, H., Ailawadi, K. L., \& van Heerde, H. J. (2017). How Well Does Consumer-Based Brand Equity Align with Sales-Based Brand Equity and Marketing-Mix Response. Journal of Marketing, 81(May), 1-20.

Duan, J.A., Sancheti, S., Sudhir, K. (2012). Predicting Individual Response with Aggregate Data: A Conditional Means Approach, Researchgate.net

Edinger-Schons, L. M., Sipil, J., Sen, S., Mende, G., \& Wieseke, J. (2018). Are Two Reasons Better Than One? The Role of Appeal Type in Consumer Responses to Sustainable Products. Journal of Consumer Psychology, 28(4), 644-664.

Fader, P. (2012). Customer Centricity, Second Edition, Philadelphia, Wharton Digital Press.

Ferris, R. (2019). Harley-Davidson's electric motorcycle signals a big change for the legendary, but troubled, company, updated 25 January 2019. https://www.cnbc.com/2018/11/09/harleydavidsons-electric-motorcycle-is-a-big-change-for-the-company. html

Godfrey, A.L. (2006). A Product Segmentation Approach and its Relationship to Customer Segmentation Approaches and Recommendations System Approaches (Doctoral dissertation). University of Texas at Austin Texas Scholar Works database.

Guadagni, P. M., \& Little, J. D. C. (1983). A Logit Model of Brand Choice Calibrated on Scanner Data. Marketing Science, 2(3), 203 238

Guitart, I. A., Gonzalez, J., \& Stremersch, S. (2018). Advertising nonpremium products as if they were premium: The impact of advertising up on advertising elasticity and brand equity. International Journal of Research in Marketing, 28, 471-489.

Holm, M., Kumar, V., \& Rohde, C. (2012). Measuring Customer Profitability in Complex Environments: An Interdisciplinary Contingency Framework. Journal of the Academy of Marketing Science, 40(3), 387-401.

Homburg, C., Steiner, V. V., \& Totzek, D. (2009). Managing Dynamics in a Customer Portfolio. Journal of Marketing, 73(5 September), 70-89.

Hsieh, M.-H., Pan, S.-L., \& Setiono, R. (2004). Product-, Corporate-, and Country-Image Dimensions and Purchase Behavior: A Multicountry Analysis. Journal of the Academy of Marketing Science, $32(3), 251-270$.

Kirca, A.H., Praneet, R., Berk Talay, M., Billur Akdeniz, M. (2019). The interactive effects of product and brand portfolio strategies on brand performance: Longitudinal evidence from the U.S. automotive industry. International Journal of Research in Marketing, available online 31 October 2019, https://doi.org/10.1016/j.ijresmar.2019. 09.003

Jayachandran, S., Hewett, K., \& Kaufman, P. (2004). Customer Response Capability in a Sense-and-Respond Era: The Role of Customer Knowledge Process. Journal of the Academy of Marketing Science, 33(3), 219-233.

Johnson, M. D., \& Selnes, F. (2004). Customer Portfolio Management: Toward a Dynamic Theory of Exchange Relationships: [1]. Journal of Marketing, 68(2), 1-17.
Kamakura, W. A., \& Russell, G. J. (1993). Measuring Brand Value with Scanner Data. International Journal of Research in Marketing, 10(1), 9-22.

Kumar, V., Venkatesan, R., Bohling, T., \& Beckman, D. (2008). The Power of CLV: Managing Customer Lifetime Value at IBM. Marketing Science, 27(4), 585-599.

Luce, R. (1959). Individual Choice Behavior. New York: Wiley.

McEachern, S. (2014). Chevrolet Colorado and GMC Canyon Target Younger Buyers and Crossover Owners, Marketing Team Says, http:/gmauthority.com/blog/2014/10/chevrolet-colorado-and-gmccanyon-targets-younger-buyers-and-crossover-owners-marketingteam-says/, October 18, 2014.

McFadden, D. (1974). Conditional Logit Analysis of Qualitative Choice Behavior, in P. Zarembka. Frontiers in Econometrics, NY: Academic Press.

McKinsey \& Company (2017). Using data to get personal with consumers: An interview with Julien Boudet, http://www.mckinsey. $\mathrm{com} /$ business-functions/marketing-and-sales/our-insights/usingdata-to-get-personal

Moorman, C., \& Day, G. S. (2016). Organizing for Marketing Excellence. Journal of Marketing, 80(November), 6-35.

Mulhern, F. (1999). Customer Profitability Analysis: Measurement, Concentration and Research Directions. Journal of Interactive Marketing, 13(Winter), 25-40.

Netzer, O., Lattin, J. M., \& Srinivasan, S. (2008). A Hidden Markov Model of Customer Relationship Dynamics. Marketing Science, 27(2), 185-204.

Parasuraman, A., \& Colby, C. L. (2001). Techno-Ready Marketing: How and Why Your Customers Adopt Technology. New York: Free Press.

Park, C. S., \& Srinivasan, V. (1994). A Survey-Based Method for Measuring and Understanding Brand Equity and Its Extendibility. Journal of Marketing Research, 31(May), 271-288.

Pick, D., Thomas, J. S., Tillmanns, S., \& Krafft, M. (2016). Customer win-back: the role of attributions and perceptions in customers' willingness to return. Journal of the Academy of Marketing Science, 44, 218-240.

Reimann, M., Schilke, O., \& Thomas, J. S. (2010). Customer relationship management and firm performance: the mediating role of business strategy. Journal of the Academy of Marketing Science, 38, 326346.

Reinartz, W. J., \& Kumar, V. (2003). The Impact of Customer Relationship Characteristics on Profitable Lifetime Duration. Journal of Marketing, 67(January), 77-99.

Rust, R. T., Kumar, V., \& Venkatesan, R. (2011). Will the frog change into a prince? Predicting future customer profitability. International Journal of Research in Marketing, 28(2011), 281-294.

Rust, R. T., Zeithaml, V. A., \& Lemon, K. N. (2000). Driving Customer Equity, How Customer Lifetime Value Is Reshaping Corporate Strategy. New York: Free Press.

Sozzi, B. (2019). \$30,000 electric motorcycle must not crash and burn, Yahoo Finance, 15 July 2019. https://finance.yahoo.com/news/harley-davidsons-new-30000-electric-motorcycle-must-not-crashand-burn-142928185.html

Srinivasan, V. (1979). Network Models for Estimating Brand-Specific Effects in Multi-Attribute Marketing Models. Management Science, 25(1), 11-21.

Srinivasan, V., Park, C. S., \& Chang, D. R. (2005). An Approach to the Measurement, Analysis, and Prediction of Brand Equity and its Sources. Management Science, 51(9), 1433-1448.

Sriram, S., Balachander, S., \& Kalwani, M. U. (2007). Monitoring the Dynamics of Brand Equity Using Store Level Data. Journal of Marketing, 71(April), 61-78.

Taylor III, Alex (2013). 3 Big Questions General Motors Needs to Answer, Fortune, May 2013. https://fortune.com/2013/05/28/3big-questions-general-motors-needs-to-answer/ 
Terech, A., Bucklin, R. E., \& Morrison, D. G. (2009). Consideration, choice, and classifying loyalty. Marketing Letters, 20, 209-225.

Terho, H., \& Halinen, A. (2007). Customer Portfolio Analysis Practices in Different Exchange Contexts. Journal of Business Research, 60(2007), 720-730.

Tita, B. (2020). Harley U. S. Sales Fall a Fifth Year-New models, efforts overseas fail to make up for younger buyers' lack of enthusiasm,. The Wall Street Journal, 29 January 2020.

Venkatesan, R., \& Kumar, V. (2004). A Customer Lifetime Value Framework for Customer Selection and Resource Allocation Strategy. Journal of Marketing, 68(October), 106-125.

Wayland, M. (2013). GM Aims 2013 Buick Encore at Young Professionals, Empty Nesters, http://www.mlive.com/auto/index. ssf/2013/01/gm_aims_2013_buick_encore_at_y.html, (1/23/2013).
Welsh, J. (2013). Car Buyers are Increasingly Loyal to their Brands. Wall Street Journal http://blogs.wsj.com/drivers-seat/2013/06/05/carbuyers-are-increasingly-loyal-to-their-car-brands/ , (6/5/13).

Zeithaml, V. A., Rust, R. T., \& Lemon, K. N. (2001). The Customer Pyramid: Creating and Serving Profitable Customers. California Management Review, 43(4), 118-142.

Zhang, J. Z. (2019). Dynamic Customer Interdependence. Journal of the Academy of Marketing Science, 47, 723-746.

Publisher's note Springer Nature remains neutral with regard to jurisdictional claims in published maps and institutional affiliations. 